\title{
Exploring the relationships between pedestrian behaviours and traffic safety attitudes in six countries
}

\author{
Rich C. McIlroy ${ }^{* 1}$, Nam Vũ Hoài ${ }^{2}$, Brenda W. Bunyasi ${ }^{3}$, Usanisa Jikyong ${ }^{1}$, Gilbert O. Kokwaro ${ }^{3}$, \\ Jianping $\mathrm{Wu}^{4}$, Md. Shamsul Hoque ${ }^{5}$, Katherine L. Plant ${ }^{1}$, John M. Preston ${ }^{1}$, Neville A. Stanton ${ }^{1}$ \\ * Corresponding author: r.mcilroy@soton.ac.uk, Transportation Research Group, Boldrewood \\ Innovation Campus, Burgess Road, Southampton, SO16 7QF \\ 1. Transportation Research Group, University of Southampton, UK \\ 2. National University of Civil Engineering, Hanoi, Vietnam \\ 3. Strathmore University, Nairobi, Kenya \\ 4. Tsinghua University, Beijing, China \\ 5. Bangladesh University of Engineering Technology, Dhaka, Bangladesh
}

\section{Abstract}

The majority of cross-cultural research on traffic safety has investigated driver behaviour, yet in most low- and middle-income countries, where the weight of the road fatality burden is felt, motorisation rates are significantly lower than in higher-income countries. As such, this approach necessarily excludes large parts of the populations in those settings. In order to investigate the link between traffic safety attitudes and road user behaviours, this study used a self-report measure of pedestrian behaviour, applying it in six countries; Bangladesh, China, Kenya, Thailand, the UK, and Vietnam. Focus was on the relationships between a respondent's attitude towards risky or rule violating on-road behaviours (of other road users, or more generally, not specific to pedestrians), and the extent to which they reported performing three types of risky pedestrian behaviours (i.e., intentional rule violations, errors in judgement or memory, and aggressive behaviours). Data from a sample of 3,423 individuals was subjected to a series of regression models, revealing significant links between attitudes and pedestrian behaviours in all countries, in all three behavioural factors, after controlling for age, gender, and exposure to the road environment. Differences were found between countries in the strength of these relationships, with weaker connections between attitudes and behaviours in Kenya, and stronger connections in China (with other countries in-between the two). Results are discussed in terms of the need to understand the relationships between social cognitive constructs in the specific country in which a road safety intervention is intended to be implemented.

Keywords: Pedestrian behaviour; traffic safety attitudes; low- and middle-income countries; questionnaire survey

Cite as: McIlroy, R. C., Nam, V. H., Bunyasi, B. W., Jikyong, U., Kokwaro, G. O., Wu, J., Hoque, M.S., Plant, K.L., Preston, J.M.,. \& Stanton, N. A. (2020). Exploring the relationships between pedestrian behaviours and traffic safety attitudes in six countries. Transportation Research Part F: Traffic Psychology and Behaviour. https://doi.org/10.1016/j.trf.2019.11.006 


\section{Introduction}

The global burden of road transport is not diminishing; over the past two decades, road fatality numbers have grown (WHO, 2018). Pedestrians are disproportionately represented in these statistics, accounting for over $35 \%$ of road injury deaths worldwide; the distribution of these pedestrian fatalities is not uniform across countries, with low- and middle-income countries (LMICs) seeing especially high rates (GRSF \& IHME, 2014; WHO, 2018). In Bangladesh, for example, pedestrians account for up to $47 \%$ of on-road fatalities (Hoque \& Salehin, 2013); in East and Central Sub-Saharan Africa, over 50\% of those killed on the roads are pedestrians (GRSF \& IHME, 2014). In high-income countries, pedestrians are still over-represented; in the UK, they are around 19 times more likely to be killed per kilometre travelled than car drivers (DfT, 2017). Responsibility for road safety is of course shared across a wide variety of individuals, organisations, and entities (McIlroy et al. 2019a), and factors such as poor infrastructure and aberrant driver behaviour often having a significant in any given incident; however, one's behaviour when interacting with the road system as a pedestrian is itself is an important contributor (e.g., Rosenbloom et al. 2008; Zhou \& Horrey, 2010).

Currently, the large majority of research on road user behaviour and traffic safety focusses on the car driver. Not only can this give us just part of the picture, such a focus also introduces bias towards certain demographic groups, especially in low- and middle-income countries where private vehicle ownership (and access) is far lower. In Europe, car ownership is widespread at virtually all levels of society; in LMICs, it is not. Almost all of us, across all countries, are able to interact with the road system as a pedestrian. As such, there is a particular need in the cross-cultural traffic safety literature for studies that explore pedestrian behaviours, and the factors underlying that behaviour.

One such underlying factor (one that has received significant attention in the traffic safety domain) is attitude (e.g., Allport, 1935; Fishbein \& Ajzen, 1980; Zimbardo \& Leippe, 1991). In a traffic safety context, this has been consistently measured as an individual's attitudes towards rule violations, for example their attitude towards speeding or the non-use of the seat-belt, and their attitudes towards risky behaviours, for example overtaking on a corner, or driving for many hours without taking rest stops. Early studies on traffic safety consistently showed linkages between these types of attitudes and a person's on-road behaviours (e.g., Åberg 1993; Parker et al. 1992; 1995a; 1995b; Parker \& Manstead, 1996; Assum, 1997; West \& Hall, 1997). Results from the literature are generally in agreement; 
attitudes to rule violations and risky behaviours affect the propensity to perform such risky behaviours, and risky behaviours lead to higher crash involvement (Ulleberg and Rundmo, 2002; Iversen, 2004; Iversen \& Rundmo, 2004). Similar results have been found across a variety of settings, e.g., in Ethiopia (Mamo \& Haney, 2014), Australia (Machin \& Sankey, 2008), Iran (Mirzaei et al. 2014), Saudi Arabia (Mohamed \& Bromfield, 2017), Taiwan (Chen, 2009), Belgium (De Pelsmacker \& Janssens, 2007), France (Cestac et al. 2011; Nabi et al. 2007), Italy (Mallia et al. 2015), China (Yao \& Wu, 2012), the UK (Poulter et al. 2008), etc.

Interestingly, Lund (2006) found the attitude-behaviour link to be insignificant in Ghana. This finding was further investigated in a number of subsequent cross-cultural comparisons. Although Lund and Rundmo (2009) found attitudes to predict driver behaviour in both Ghana and Norway, the relationship was found to be significantly stronger in Norway. Similarly, Nordfjærn et al. (2011; see also Nordfjærn et al. 2014) found attitudes to predict driver behaviour across all eight countries they investigated, but that in Sub-Saharan Africa (Ghana, Tanzania, Uganda) the two were linked to a significantly lesser extent than in Norway, Russia, and India. In all cases, the attitudes measure referred to driving rule violations and speeding, with some items on general risk behaviours included.

In those studies, the focus was on the car driver. Given low vehicle ownership rates in many low- and middle-income countries (LMICs), this focus excludes large parts of the population in those settings. Although not as common as driver behaviour research, questionnaire-based research into pedestrian behaviours can be found (e.g., Atić et al. 2016). In a study reported by Şimşekoğlu (2015), respondents were asked about their behaviours both as car drivers and as pedestrians. Results showed strong relationships between all dimensions of self-reported behaviour, indicating that the tendency to take risks as a driver and the tendency to do so as a pedestrian are highly correlated. Additionally, Şimşekoğlu (2015) found that attitudes to on-road pedestrian safety, measured by the extent to which respondents agreed with statements like 'it is difficult to obey the traffic rules related to pedestrians because they are very complicated' and 'it is acceptable to violate the rules as a pedestrian when I am in a hurry', were a strong predictor of self-reported pedestrian behaviours. This finding, in line with those found for car drivers, has also been reported elsewhere; pedestrians' intentions to perform risky behaviours (such as crossing the road at inopportune moments or unsafe locations) are significantly predicted by their attitudes towards those types of behaviours (Díaz, 2002; Evans \& Norman, 1998; Zhou \& Horrey, 2010). 
Cultural factors have also been taken into consideration; Nordfjærn and Şimşekoğlu (2013) looked at the relationships between attitudes towards pedestrian rule violations and risk behaviours (using the same attitudes scale as that reported in Şimşekoğlu, 2015), the selfreported performance of such pedestrian behaviours, and cultural factors (primarily collectivism). Not only did attitudes predict behaviour, they found that culture explained additional variance (Nordfjærn and Şimşekoğlu, 2013); however, this study took as its sample respondents from only Turkey. One study that was undertaken across different countries was reported by Papadimitriou et al. (2013). In a large questionnaire-based interview study, conducted across 19 European countries, pedestrian attitudes were again found to strongly relate to their behaviours; however, there was no exploration of the potential country differences in the extent to which attitudes were associated with behaviours (in pedestrians or in other road user groups; see Cestac \& Delhomme, 2012).

To our knowledge, the only study that has made comparisons across countries with respect to pedestrian behaviours and attitudes was reported by Nordfjærn and Zavareh (2016); again, the same attitudes scale was used that that reported in Nordfjærn and Şimşekoğlu (2013) and Şimşekoğlu (2015). In a survey of young adults in Iran and Pakistan, the authors found that despite differences in reported risk-taking behaviours across the two countries, attitudes to safety did not significantly differ. Moreover, attitudes predicted selfreported behaviours in both settings (Nordfjærn and Zavareh, 2016), though the relationship was slightly stronger in Iran (a higher income country).

In terms of country comparisons, Iran and Pakistan share some common characteristics. They are neighbouring countries, both of which have predominantly Muslim populations (though the Shia branch of Islam dominates in Iran, whereas the majority of Pakistanis are Sunni), and both are categorised as middle-income countries (though Pakistan is lowermiddle income, and Iran upper-middle; World Bank, 2019). To our knowledge, there as yet exists no published work making comparisons of pedestrian behaviour and attitudes to traffic safety across a wider variety of countries, ones that exhibit greater differences in geography, economy, culture, and motorisation and road safety statistics. Additionally, all the aforementioned studies on pedestrian attitudes and behaviours looked specifically at the relationships between attitudes to pedestrian behaviours and rule following and the selfreported performance of those behaviours. None explored the broader relationships between a person's self-reported behaviours when interacting with the road system as a pedestrian, and their general attitudes to traffic safety and rules, including those relating to motorised vehicle use. 
A person's lack of access to, or experience in driving a private motor vehicle does not preclude them having valid experiences, opinions, and concerns about the use of such vehicles. For example, many people use public transport and shared taxis, and the use of chauffeurs among the middle classes is common in many regions (for example, in Bangladesh and India). A lack of experience driving, and access to a car does, however, preclude a person from responding to a questionnaire asking for self-reports of driving behaviours. Given that the majority of people can and do (at some point) interact with the roads system as a pedestrian, the current research looks at how self-reported pedestrian behaviours relate to attitudes towards risky behaviours and rule violations performed by those in control of a motorised vehicle. A deeper understanding of these relationships, and how they might differ across cultural contexts, could guide the decision-making processes of intervention designers and policy makers when considering how best to affect the overall road safety system in their country of application, without restricting findings to small, potentially unique groups (i.e., private vehicle drivers).

To address this gap in the literature a questionnaire survey was administered in six countries; Bangladesh, China, Kenya, Thailand, the UK, and Vietnam. These countries were chosen as being part of a larger project taking a sociotechnical systems perspective of road safety in low- and middle-income countries (NIHR, 2017; McIlroy, et al. 2019a). Table 1 briefly summarises each country in terms of demographics, economics, motorisation rates, and road safety statistics.

Table 1. Summary of statistics for countries involved in the research.

\begin{tabular}{|c|c|c|c|c|c|c|}
\hline & Bangladesh & China & Kenya & Thailand & $\begin{array}{c}\text { United } \\
\text { Kingdom } \\
\end{array}$ & Vietnam \\
\hline Population (million people) & 163.0 & $1,411.4$ & 48.5 & 68.8 & 65.8 & 94.6 \\
\hline $\begin{array}{l}\text { Gross National Income per } \\
\text { capita in USD }\end{array}$ & 1,330 & 8,260 & 1,380 & 5,640 & 42,390 & 2,050 \\
\hline People per registered vehicle & 57 & 4.8 & 16.3 & 1.8 & 1.8 & 1.9 \\
\hline $\begin{array}{l}\text { Estimated road traffic death rate } \\
\text { per } 10,000 \text { vehicles }\end{array}$ & 86.7 & 8.7 & 45.2 & 6.0 & 0.53 & 4.9 \\
\hline $\begin{array}{l}\text { Estimated road traffic death rate } \\
\text { per } 100,000 \text { population }\end{array}$ & 15.3 & 18.2 & 27.8 & 32.7 & 3.1 & 26.4 \\
\hline
\end{tabular}

Notes: All data come from WHO (2018) and are for the year 2016. 'Vehicles' include motorised two- and three-wheelers, cars and four-wheeled light vehicles, trucks, buses, and other motorised vehicles (WHO, 2018). 
The primary aims of the research presented herein were twofold; first, to assess the differences in attitudes to rule violating or risky on-road behaviours across the countries presented in Table 1; second, to investigate the relationships between these attitudes and a person's self-reported pedestrian behaviours, and whether those relationships differ across the countries investigated. Given the mixed results in the literature concerning cross-cultural differences in driver attitudes (Nordfjærn et al. 2011; 2014) we make no specific hypotheses with respect to attitudes scores taken alone. Following the literature discussed above, in which the attitude-behaviour link was found to be weaker in lower-income settings compared to high-income settings (Lund and Rundmo, 2009; Nordfjærn et al. 201; Nordfjærn et al. 2014; and Nordfjærn and Zavareh, 2016), we hypothesise that attitudes will explain variance in self-reported pedestrian behaviour across all countries, but that this relationship will be stronger in higher-income countries.

\section{Method}

\subsection{Survey instrument}

The questionnaire sections on attitudes to traffic safety and self-reported pedestrian behaviour used in this study were part of a larger questionnaire comprising sections on demographics, transport choices and experience, attitudes, risk perceptions, beliefs, and self-reported pedestrian behaviours (other aspects of which have been reported elsewhere, e.g., McIlroy et al. 2019b, Dinh et al. forthcoming).

The demographics section included questions regarding gender, age, socioeconomic status, education, income level, religion, and experience on the roads. Then followed the attitudes section. All gave statements of behaviours that violate rules or could be considered as risky (e.g., Q2.1 "Many traffic rules must be ignored to ensure flow"), and asked the respondent to rate (on a five-point Likert scale) how much they agreed with each (from 'strongly agree' to 'strongly disagree'). Of the 22 questions used in this section, 15 were taken from the 16 described by Iversen and Rundmo (2004). We did not use the question 'I would never drive after drinking alcohol' as this is not appropriate in a country such as Bangladesh, where alcohol is (in practical terms) prohibited for Bangladeshi nationals (the intended respondents to the questionnaire in that country). Moreover, the question refers specifically to the respondent performing a driving behaviour, and is therefore inappropriate for those not able to drive a car. Following discussions with colleagues in Bangladesh and other countries, a compromise was reached to include the question 'I would never ride with 
someone I knew had been drinking alcohol'. It is still possible that some individuals use alcohol in Bangladesh, and it is a common theme across all other countries. Of the remaining seven questions in this section, four were taken from Peltzer and Renner (2003), two were created for this study based on discussions with colleagues in each of the countries. These two questions related to attitudes towards riding a motorbike without a helmet, and wearing a seatbelt when travelling in a car. Although many of the questions referred to behaviours exhibited when in control of a vehicle (e.g., 'It is acceptable to drive when traffic lights shift from yellow to red'), specific references to private cars were removed or altered such that questions could be interpreted as referring to motorcyclists, buses, or other motorised vehicles (for example). As such, questions aimed at garnering respondents' general attitudes to the behaviours exhibited by different road users. For brevity, we herein refer to the measure as attitudes towards traffic safety; this is the term used by Iversen and Rundmo (2004), from where the majority of items were taken.

To measure pedestrian behaviour, the short version of the Pedestrian Behaviour Questionnaire reported by Deb et al. (2017) was used. This is a slightly modified version of the questionnaire used in the aforementioned Nordfjærn and Şimşekoğlu (2013), Şimşekoğlu (2015), and Nordfjærn and Zavareh (2016) studies. The short version of the questionnaire contains 20 items that ask respondents to indicate how often they would perform a given behaviour (e.g., 'I cross diagonally to save time') on a six-point Likert scale, from 'extremely infrequently or never' to 'extremely frequently or always'. In Deb et al.'s 20 -item version, one of the questions refers to crossing a road when the (pedestrian) light is red. This is not a violation of law in many countries, and is not appropriate in countries where pedestrian traffic lights are very uncommon, or rarely functioning (e.g., in Bangladesh and Kenya in particular). Following discussions between researchers in the six countries this question was exchanged with another (from the larger, 50-item set described by Deb et al. 2017) that concerns the non-use of pedestrian footbridges or underpasses, a common theme in many low- and middle-income countries.

The questionnaire was first compiled in English and then translated into Bengali, Mandarin Chinese, Kiswahili, Thai, and Vietnamese. Translations proceeded in accordance with Brislin (1970). The English language version was first translated into the target language by one bi-lingual individual. The translation was then viewed by another bi-lingual individual, one who had not seen the original English version, and back-translated into English. The original and back-translated versions were compared and any inconsistencies 
discussed between researchers in the UK and in the non-English speaking country until a satisfactory translation was attained.

\subsection{Survey administration and respondents}

In the UK, the questionnaire was administered online and on paper. The University of Southampton's iSurvey platform was used to host the online version, and was advertised using open and private access social media. The online questionnaire was available from April to September, 2018. To gather paper-based responses researchers went to commercial centres in and around the UK city of Southampton and handed out surveys to willing passersby, and to shops and cafés for staff members and customers to complete. All paper-based questionnaires were distributed and collected between June and August, 2018.

In Bangladesh, paper-based responses were collected from Dhaka city and its neighbouring districts. Respondents were either given questionnaires which were then completed and collected at a later date, or individuals were interviewed, with the researcher marking answers on the paper forms for the respondent (in cases where participants were illiterate or simply desired for it to be undertaken this way). Data collection outside Dhaka city took place between March and April, 2018. In the city, data collection took place between August and September, 2018. No online questionnaire was used.

The Wenjuanxing online survey platform (www.wjx.cn) hosted and advertised the questionnaire in China. A link was also advertised using social media. All respondents completed the questionnaire online, and all data were collected between April and September, 2018. The University of Southampton's iSurvey platform was used to host the Thai version of the survey. A link to the survey was advertised on social media, both in public access and closed groups, with data collection continuing from May to July, 2018.

In Kenya, paper-based responses were collected in Nairobi city. Students and employees of Strathmore University were approached and briefed on the project. They were given either hard copies of the questionnaire and asked to return them once complete, or were given access to online questionnaires. Additionally, social media was used to advertise a link to an online version. All data were collected between April and September, 2018.

A paper version of the questionnaire was used to collect all responses in Vietnam. Researchers in Hanoi went out to public places and handed out questionnaires to passers-by, and gave questionnaires to acquaintances to complete themselves and to pass on to friends and family members. Individuals either completed the questionnaires themselves while the researcher waited, were 'interviewed' (i.e. questions read out to them, and responses recorded 
on paper by the researcher), or questionnaires were handed out to be taken away, and an appointment made for collection of the completed forms at a later date. Data were gathered from April to September, 2018.

All participants provided fully informed consent, and ethical approval was sought from, and granted by the University of Southampton's ethics board (ID: 40682). Additional ethical approval was sought from, and granted by the Strathmore University Ethics Committee and the National Commission for Science and Technology, in Kenya (ID: SU-IRB 0214/18).

Following removal of 44 respondents from the Kenyan sample (due to large numbers of missing items), 3423 responses were collated for analysis; 695 from the UK, 532 from Bangladesh, 544 from China, 500 from Kenya, 317 from Thailand, and 835 from Vietnam. Of these respondents, 22 did not answer one or both of the age and gender questions, and ten indicated 'Prefer not to say' or 'Other' to the gender question. The remaining 3,391 are summarised in Table 2.

Table 2. Age and gender characteristics of the samples from each of the six countries. Percentages are with respect to the total number of respondents who answered both age and gender questions, and identified as either male or female.

\begin{tabular}{|c|c|c|c|c|c|c|c|}
\hline & & $18-24$ & $25-34$ & $35-44$ & $45-54$ & Over 54 & Totals \\
\hline \multirow[b]{2}{*}{ Bangladesh } & Male & $161(30 \%)$ & $111(21 \%)$ & $61(11 \%)$ & $49(9 \%)$ & $37(7 \%)$ & $419(79 \%)$ \\
\hline & Female & $55(10 \%)$ & $29(5 \%)$ & $10(2 \%)$ & $12(2 \%)$ & $7(1 \%)$ & $113(21 \%)$ \\
\hline \multirow[b]{2}{*}{ China } & Male & $23(4 \%)$ & $113(21 \%)$ & $78(14 \%)$ & $12(2 \%)$ & $3(<1 \%)$ & $229(42 \%)$ \\
\hline & Female & $60(11 \%)$ & $189(35 \%)$ & $51(9 \%)$ & $13(2 \%)$ & $1(<1 \%)$ & $314(58 \%)$ \\
\hline \multirow[b]{2}{*}{ Kenya } & Male & $159(32 \%)$ & $48(10 \%)$ & $16(3 \%)$ & $5(1 \%)$ & $5(1 \%)$ & $233(47 \%)$ \\
\hline & Female & $172(34 \%)$ & $49(10 \%)$ & $31(6 \%)$ & $13(3 \%)$ & $2(<1 \%)$ & $267(53 \%)$ \\
\hline \multirow[b]{2}{*}{ Thailand } & Male & $6(2 \%)$ & $46(15 \%)$ & $31(10 \%)$ & $11(4 \%)$ & $25(8 \%)$ & $119(38 \%)$ \\
\hline & Female & $3(1 \%)$ & $85(27 \%)$ & $62(20 \%)$ & $19(6 \%)$ & $26(8 \%)$ & $195(62 \%)$ \\
\hline \multirow[b]{2}{*}{ UK } & Male & $64(10 \%)$ & $55(8 \%)$ & $45(7 \%)$ & $54(8 \%)$ & $85(13 \%)$ & $303(45 \%)$ \\
\hline & Female & $103(15 \%)$ & $116(17 \%)$ & $47(7 \%)$ & $45(7 \%)$ & $53(8 \%)$ & $364(55 \%)$ \\
\hline \multirow[b]{2}{*}{ Vietnam } & Male & $178(21 \%)$ & $105(13 \%)$ & $81(10 \%)$ & $74(9 \%)$ & $54(6 \%)$ & $492(59 \%)$ \\
\hline & Female & $80(10 \%)$ & $89(11 \%)$ & $77(9 \%)$ & $64(8 \%)$ & $33(4 \%)$ & $343(41 \%)$ \\
\hline \multirow{3}{*}{ Total } & Male & $591(17 \%)$ & $478(14 \%)$ & $312(9 \%)$ & $205(6 \%)$ & $209(6 \%)$ & $1795(53 \%)$ \\
\hline & Female & $473(14 \%)$ & $557(16 \%)$ & $278(8 \%)$ & $166(5 \%)$ & $122(4 \%)$ & $1596(47 \%)$ \\
\hline & All & $1064(31 \%)$ & $1035(31 \%)$ & $590(17 \%)$ & 371 (11\%) & $331(10 \%)$ & $3391(100 \%)$ \\
\hline
\end{tabular}

Regarding the way in which respondents interacted with the road systems of their country, large difference between sample were found. The was as expected, and reflects differences in the road system (and its usage) of each of the countries included. For example, in Vietnam, the majority of respondents indicated 'motorcycle - rider' as their most common form of transport, whereas in Kenya 'bus or train - passenger' was most common. Results are displayed in Table 3. In Bangladesh, of the 223 respondents listed under 'Other', 121 stated 'bicycle rickshaw - passenger' as their most commonly used means of transport, and 75 
indicated 'motorised three-wheeler - passenger'. In terms of exposure to the road system, respondents were asked how much time they spent travelling each week; results are summarised in Table 4. Significant differences between the country samples were again seen; a Kruskall-Wallis test revealed these differences to be statistically significant $\left(\chi^{2}{ }_{(5)}=81.8, p\right.$ $<.001)$.

Table 3. Responses to the question concerning respondents most commonly used means of transport. Percentages are with respect to the 3,410 respondents who answered the question.

\begin{tabular}{rccccccc}
\hline & Bangladesh & China & Kenya & Thailand & UK & Vietnam & Totals \\
\hline $\begin{array}{r}\text { Car driver } \\
\text { Bus or train } \\
\text { passenger }\end{array}$ & $115(2 \%)$ & $307(56 \%)$ & $103(21 \%)$ & $228(73 \%)$ & $374(54 \%)$ & $91(11 \%)$ & $1113(33 \%)$ \\
$\begin{array}{r}\text { Motorcycle rider } \\
\text { Pedestrian }\end{array}$ & $35(7 \%)$ & $15(3 \%)$ & $9(2 \%)$ & $17(5 \%)$ & $19(3 \%)$ & $556(67 \%)$ & $651(19 \%)$ \\
Cyclist & $49(9 \%)$ & $29(5 \%)$ & $7(1 \%)$ & $0(0 \%)$ & $72(11 \%)$ & $62(7 \%)$ & $219(6 \%)$ \\
$\begin{array}{r}\text { Car passenger } \\
\text { Motorcycle } \\
\text { passenger }\end{array}$ & $48(9 \%)$ & $56(10 \%)$ & $43(9 \%)$ & $19(6 \%)$ & $23(23 \%)$ & $10(1 \%)$ & $199(6 \%)$ \\
$\begin{array}{r}\text { Other (passenger } \\
\text { or driver) }\end{array}$ & $223(42 \%)$ & $6(1 \%)$ & $14(3 \%)$ & $1(<1 \%)$ & $7(1 \%)$ & $5(<1 \%)$ & $250(1 \%)$ \\
Totals & $530(16 \%)$ & $544(16 \%)$ & $500(15 \%)$ & $314(9 \%)$ & $687(20 \%)$ & $835(24 \%)$ & $3410(100 \%)$ \\
\hline
\end{tabular}

Table 4. Responses to the question asking about respondents' time spent travelling each week, across the six countries. Percentages are with respect to the 3,421 respondents who answered this question.

\begin{tabular}{rccccccc}
\hline & Bangladesh & China & Kenya & Thailand & UK & Vietnam & Totals \\
\hline Less than 1 hour & $42(8 \%)$ & $29(5 \%)$ & $60(12 \%)$ & $55(17 \%)$ & $17(2 \%)$ & $28(3 \%)$ & $231(7 \%)$ \\
1 to 3 hours & $119(22 \%)$ & $84(15 \%)$ & $131(26 \%)$ & $96(30 \%)$ & $138(20 \%)$ & $95(11 \%)$ & $663(19 \%)$ \\
3 to 6 hours & $126(24 \%)$ & $108(20 \%)$ & $96(19 \%)$ & $46(15 \%)$ & $228(33 \%)$ & $253(30 \%)$ & $857(25 \%)$ \\
6 to 10 hours & $103(19 \%)$ & $153(28 \%)$ & $96(19 \%)$ & $41(13 \%)$ & $162(23 \%)$ & $242(29 \%)$ & $797(23 \%)$ \\
10 to 15 hours & $63(12 \%)$ & $112(21 \%)$ & $60(12 \%)$ & $32(10 \%)$ & $82(12 \%)$ & $110(13 \%)$ & $459(13 \%)$ \\
15 to 20 hours & $19(4 \%)$ & $35(6 \%)$ & $25(5 \%)$ & $25(8 \%)$ & $30(4 \%)$ & $107(13 \%)$ & $241(7 \%)$ \\
More than 20 hours & $59(11 \%)$ & $23(4 \%)$ & $32(6 \%)$ & $22(7 \%)$ & $37(5 \%)$ & $0(0 \%)$ & $173(5 \%)$ \\
Totals & $531(16)$ & $544(16 \%)$ & $500(15 \%)$ & $317(9 \%)$ & $694(20 \%)$ & $835(24 \%)$ & $3421(100 \%)$ \\
\hline
\end{tabular}




\subsection{Statistical analyses}

To assess the suitability of the attitudes scale, Confirmatory Factor Analysis (CFA) was performed using the AMOS (v.24) software package. Given that all items aimed at measuring general attitudes towards traffic safety, it was considered appropriate to investigate the suitability of a single underlying factor in this way. Items found to have factor loadings lower than 0.4 were removed (e.g., Field, 2018; Ertz et al. 2016). Modification indices were consulted and, where strong similarities between wording and content were found, covariances between items were added. Good model fit cannot generally be judged by one CFA index alone, rather the reporting of multiple indices is recommended (Hooper et al. 2008); as such, we report below relative chi square ( $\left.x^{2} / \mathrm{df}\right)$, adjusted goodness-of-fit index (AGFI), comparative fit index (CFI), root mean square error of approximation (RMSEA), and standardised root mean square residual (SRMR). Accepted values for good model fit are as follows: $x^{2} / \mathrm{df} \leq 3, \mathrm{AGFI} \geq 0.95, \mathrm{CFI} \geq 0.95$, RMSEA $\leq 0.07$, SRMR $\leq 0.08$ (all thresholds from Hooper et al. 2008), with $\mathrm{Hu}$ and Bentler (1999) suggesting a two-index strategy whereby model fit can be accepted if RMSEA is below 0.06 and SRMR is below 0.09 .

For all latent factors included in the analyses (i.e., attitudes and the three behavioural factors), internal consistency, or reliability, was assessed using Cronbach's alpha $(\alpha)$. Reliability of a scale is generally considered acceptable when over .7 (e.g., Nunally, 1978). To assess differences in attitudes scores across countries, Analyses of Variance (ANOVA) was used, while for the exploration of the extent to which attitudes could explain variance in self-reported behaviours across countries (and the differences therein), hierarchical regression (forced entry method) was used. Both types of analyses were performed using SPSS (v.24) and are explained in more detail in their respective sections, below.

\section{Results}

\subsection{Data reduction}

Regarding the attitudes towards traffic safety section, due to technical problems, the Thai sample did not include data for question 22 ('It is acceptable to ride a bicycle without a helmet'); as such, this question was excluded from all subsequent analyses. To deal with missing data points in CFA, cases were deleted listwise, hence the CFA was performed on a sample of 3330. Eight items were found to have factor loadings lower than .4, hence were removed. Based on the modification indices, three error co-variance relationships were added (see Figure 1). 
Although the relative chi square index was rather high, the resulting model (the standardised solution to which is displayed in Figure 1) showed good model fit following most indices, and satisfied Hu and Bentler's (1999) two-index strategy. As such, a single underlying factor was accepted, and a single score for attitudes towards traffic safety was calculated for each participant by averaging across the items included in Figure 1. Reliability analyses revealed the scale to have acceptable internal consistency; across all countries' data together $(\alpha=.805)$ and individually (in Bangladesh, $\alpha=.762$; in China, $\alpha=.746$; in Kenya, $\alpha$ $=.784$; in Thailand, $\alpha=.813$; in the UK, $\alpha=.828$; and in Vietnam, $\alpha=.787$ ). Means and standard deviations for all questions are displayed in Table 2. Higher scores correspond to safer attitudes (possible scores from one to five).

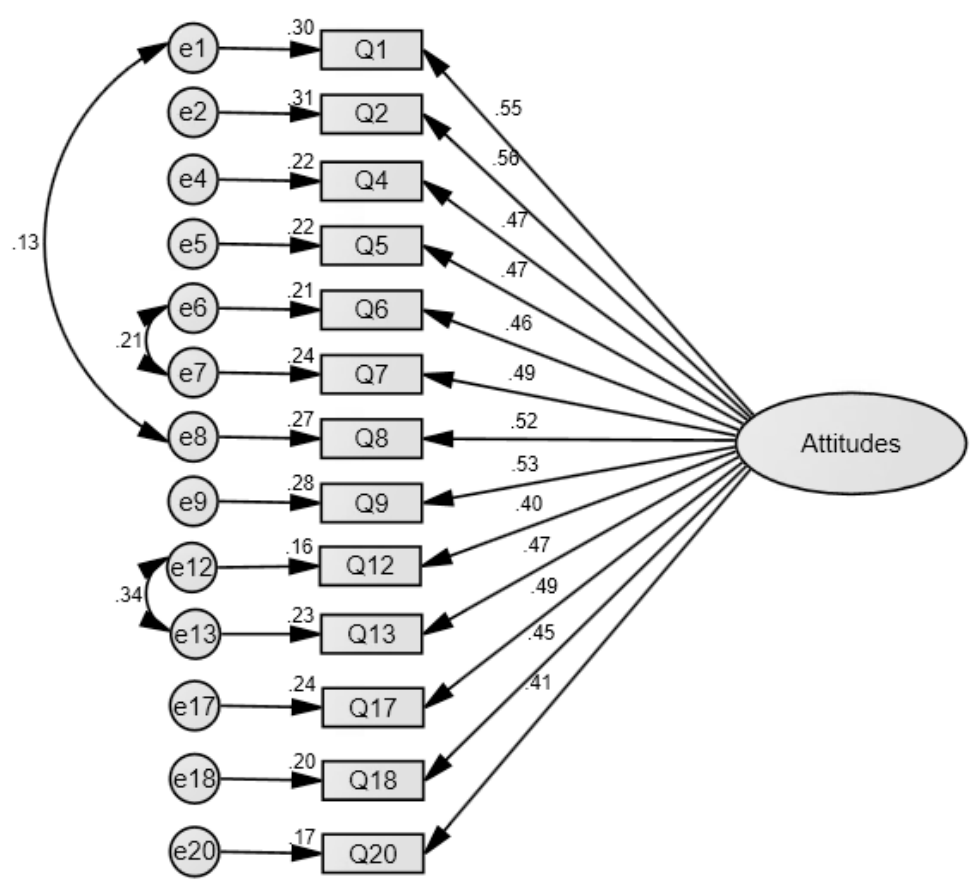

Figure 1. Standardised solution to the one-factor Attitudes model. $\mathrm{df}=62, x^{2} / \mathrm{df}=10.504$, $\mathrm{AGFI}=.956, \mathrm{CFI}=.923, \mathrm{RMSEA}=.053(p=.062), \mathrm{SRMR}=.0359$. 
Table 2. Means and standard deviations for the 21 attitudes questions. Number indicates question order.

\begin{tabular}{|c|c|c|c|}
\hline No. & Question & $M$ & $S D$ \\
\hline \multicolumn{4}{|c|}{ Included in the scale } \\
\hline 1 & Many traffic rules must be ignored to ensure traffic flow & 3.85 & 1.208 \\
\hline 2 & It makes sense to exceed speed limits to get ahead of slow drivers & 3.53 & 1.213 \\
\hline 4 & Speed limits are exceeded because they are too restrictive & 3.45 & 1.153 \\
\hline 5 & It is acceptable to drive when traffic lights shift from yellow to red & 3.88 & 1.153 \\
\hline 6 & Taking chances and breaking a few rules does not necessarily make bad drivers & 3.38 & 1.203 \\
\hline 7 & It is acceptable to take chances when no other people are involved & 3.75 & 1.188 \\
\hline 8 & Traffic rules are often too complicated to be carried out in practice & 3.65 & 1.158 \\
\hline 9 & If you are a good driver it is acceptable to drive a little faster & 3.58 & 1.152 \\
\hline 12 & I will ride with someone who speeds if that's the only way to get home at night & 3.70 & 1.132 \\
\hline 13 & I will ride with someone who speeds if others do & 3.90 & 1.009 \\
\hline 17 & When the road is clear, there is no need to stop at a stop sign & 4.02 & 1.077 \\
\hline 18 & Towards the crest of a hill, a driver should overtake the vehicle in front if they are going faster & 4.28 & .946 \\
\hline 20 & It is acceptable to ride on a motorbike without a helmet & 4.34 & .921 \\
\hline \multicolumn{4}{|c|}{ Excluded from the scale } \\
\hline 3 & Traffic rules must be respected regardless of road and weather conditions & 4.08 & 1.124 \\
\hline 10 & When road conditions are good and nobody is around driving at $100 \mathrm{mph}(\sim 160 \mathrm{kmh})$ is ok & 3.97 & 1.188 \\
\hline 11 & Punishments for speeding should be more severe & 3.61 & 1.216 \\
\hline 14 & I don't want to risk my life and health by riding with an irresponsible driver & 4.35 & 1.055 \\
\hline 15 & I would never ride with someone I knew has been drinking alcohol & 4.26 & 1.114 \\
\hline 16 & One should be able to drive at the car's maximum speed & 4.10 & 1.096 \\
\hline 19 & During a long trip a driver should stop as little as possible in order not to lose time & 3.71 & 1.220 \\
\hline 21 & You should always wear your seatbelt when travelling in a car & 4.36 & 1.018 \\
\hline
\end{tabular}

Data reduction activities concerning the Pedestrian Behaviour Questionnaire (PBQ) section are reported in full elsewhere (Mcllroy et al. 2019b). Following those analyses, three of the five factors included in Deb et al.'s (2017) version of the PBQ were used for analysis. Results from the items used are displayed in Table 3, grouped by factors, alongside Cronbach alpha values for each factor, and means and standard deviations for each question. For all three sections, higher scores correspond to more undesirable or riskier behaviours (with scores ranging from one to six). Although the reliability (i.e., Cronbach's alpha) of the violations scale was lower than the normally accepted threshold of .7, it was considered sufficiently close in this exploratory context to merit its continued inclusion in subsequent analyses. The reader is, however, advised to consider results concerning violations more cautiously. 
Table 3. Factor groupings, Cronbach's alpha, means and standard deviations for the PBQ section. Numbers in the left column indicate original question order (see also McIlroy et al. 2019b).

\begin{tabular}{|c|c|c|c|}
\hline & & $M$ & $S D$ \\
\hline & Violations $(\alpha=0.689)$ & & \\
\hline 3 & I cross diagonally to save time & 2.94 & 1.414 \\
\hline 4 & I cross outside the pedestrian crossing even if there is one (e.g., a crosswalk or zebra crossing) less than $50 \mathrm{~m}$ away & 2.73 & 1.373 \\
\hline 7 & I avoid using pedestrian bridges or underpasses for convenience, even if one is located nearby & 2.52 & 1.374 \\
\hline \multirow[t]{2}{*}{10} & I take passageways forbidden to pedestrians to save time & 1.93 & 1.234 \\
\hline & Aggressive Behaviours $(\alpha=0.785)$ & & \\
\hline 9 & I get angry with another road user (pedestrian, driver, cyclist, etc.), and I yell at them & 1.90 & 1.196 \\
\hline 12 & I cross very slowly to annoy a driver & 1.50 & 1.006 \\
\hline 14 & I get angry with another road user (pedestrian, driver, cyclist, etc.), and I make a hand gesture & 1.81 & 1.188 \\
\hline \multirow[t]{2}{*}{19} & I have gotten angry with a driver and hit their vehicle & 1.45 & .973 \\
\hline & Lapses $(\alpha=0.852)$ & & \\
\hline 13 & I realize that I have crossed several streets and intersections without paying attention to traffic & 2.10 & 1.237 \\
\hline 15 & I forget to look before crossing because I am thinking about something else & 2.01 & 1.162 \\
\hline 16 & I cross without looking because I am talking with someone & 1.91 & 1.110 \\
\hline 17 & I forget to look before crossing because I want to join someone on the pavement on the other side & 1.83 & 1.143 \\
\hline
\end{tabular}

\subsection{Group differences}

Looking at respondents' attitudes to traffic safety scores, a number of significant differences were found between the country samples. Kenyan respondents reported significantly safer attitudes $(\mathrm{M}=4.14, \mathrm{SD}=.63)$ than those in any other country; this difference was significant at $p=.045$ for the comparison with respondents in China $(\mathrm{M}=$ $4.04, \mathrm{SD}=.42)$, and at the $p<.001$ level for the comparisons with those in the UK $(\mathrm{M}=$ $3.84, \mathrm{SD}=.58)$, Thailand $(\mathrm{M}=3.68, \mathrm{SD}=.57)$, Bangladesh $(\mathrm{M}=3.65, \mathrm{SD}=.70)$, and Vietnam $(\mathrm{M}=3.51, \mathrm{SD}=.52)$. Those in China reported significantly safer attitudes than in any other country except Kenya (all at $p<.001$ ); those in the UK reported significantly safer attitudes than those in Thailand, Bangladesh, or Vietnam (all at $p<.001$ ); those in Thailand and Bangladesh did not significantly differ from each other, but both samples reported significantly safer attitudes than those in Vietnam (both at $p<.001$ ). Figure 2 displays these results graphically. 


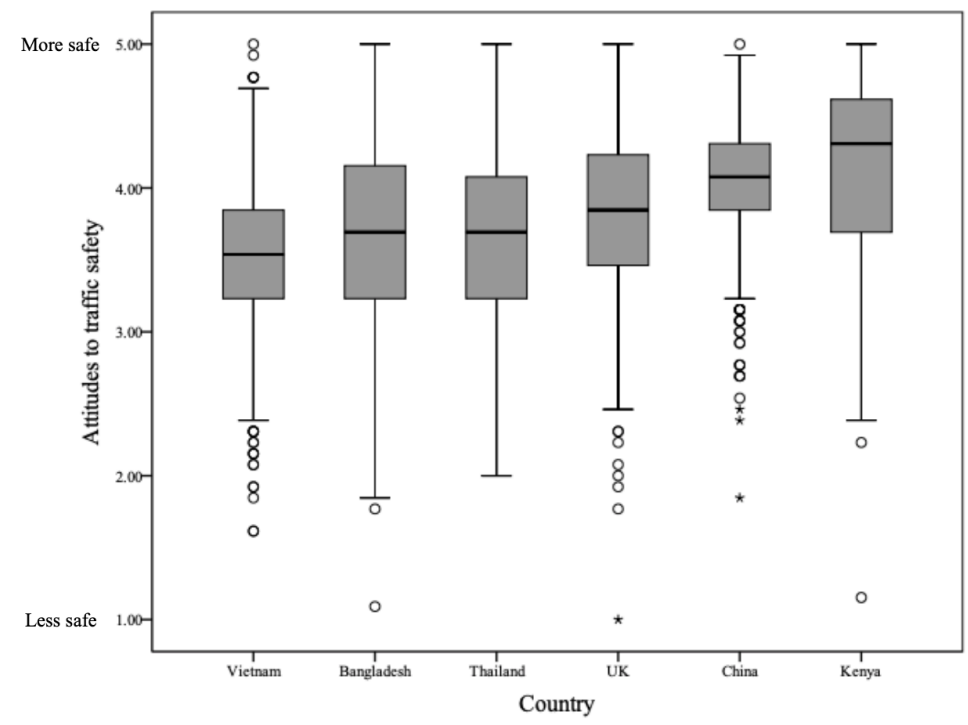

Figure 2. Attitudes score by country. Circles and asterisks indicate outliers at more than 1.5 and 3 times the interquartile range respectively.

To assess the relationships between attitudes to traffic safety and pedestrian behaviour across the six countries, a series of bivariate correlations were assessed. Results for all countries' data together and individually are summarised in Table 4. Attitudes to traffic safety were significantly correlated with the self-reported performance of all three PBQ factors. These relationships were strongest in the Thailand sample, and weakest in the Kenya sample. In all instances, safer attitudes related to a lower self-reported propensity to perform undesirable pedestrian behaviours.

Table 4. Correlations between Attitudes and the three PBQ factors

\begin{tabular}{lccc}
\hline & \multicolumn{3}{c}{ Pearson's $R$ correlations between } \\
& Violations & Aggressions & Lapses \\
\hline Bangladesh & -.212 & -.262 & -.212 \\
China & -.363 & -.322 & -.374 \\
Kenya & -.182 & -.179 & -.137 \\
Thailand & -.435 & -.275 & -.318 \\
UK & -.327 & -.237 & -.322 \\
Vietnam & -.425 & -.247 & -.275 \\
All Countries & -.280 & -.177 & -.247 \\
\hline
\end{tabular}

Note: All correlations significant at $p<.001$ except for Lapses in Kenya $(p=.002)$.

To assess the extent to which variance in the three pedestrian behaviour factors was explained by respondents' attitudes scores in each country, together and individually, a series of multiple regression analyses was performed. Hierarchical linear regression using the forced entry method was adopted. Given country differences in the age and gender splits, these were included in the first block. Similarly, significant differences in exposure to the 
road system were reported by respondents of different countries (see above, Section 3.2), hence this was included in the second block. Finally, the attitudes variable was added in the third block in order to assess the extent to which it explained variance in each of the three pedestrian behaviours, over and above the effects of age, gender, and exposure. Tables 5 to 7 , each corresponding to one of the pedestrian behaviour factors, presents the $\mathrm{R}^{2}$ values for the first step (i.e., age and gender as predictors of the PBQ factor), and the changes in $\mathrm{R}^{2}$ upon addition of exposure as a predictor variable (Step 2), then attitudes to road safety (Step 3). Total $\mathrm{R}^{2}$, indicating the total amount of variance in the pedestrian behaviour factors explained by age, gender, exposure, and attitudes to traffic safety, is also shown in each.

Attitudes were found to explain significant additional variance over age, gender, and exposure (i.e., Step $3 \Delta \mathrm{R}^{2}$ ) in all three behavioural factors, in all countries; results were significant at $p<.001$ in all countries with the exception of Kenya, where for violations the relationship was significant at $p=.001$, for aggressions $p=.003$, and for lapses $p=.043$.

Table 5. Regression results for explaining variance in violation scores; Step 1 - age and gender; Step 2 - age, gender, and exposure; Step 3 - age, gender, exposure, and attitudes

\begin{tabular}{lcccc} 
& Step $1 R^{2}$ & Step $2 \Delta R^{2}$ & Step $3 \Delta R^{2}$ & Total $R^{2}$ \\
\hline Bangladesh & $.024^{*}$ & .002 & $.042^{* * *}$ & $.068^{* * * *}$ \\
China & .006 & $.012^{*}$ & $.127^{* * *}$ & $.145^{* * *}$ \\
Kenya & $.031^{* *}$ & $.008^{*}$ & $.023^{* *}$ & $.061^{* * *}$ \\
Thailand & .035 & $.018^{* * *}$ & $.167^{* * *}$ & $.220^{* * * *}$ \\
UK & $.066^{* * *}$ & .001 & $.094^{* * *}$ & $.161^{* * *}$ \\
Vietnam & .019 & $<.001$ & $.171^{* * *}$ & $.190^{* * *}$ \\
All Countries & $.032^{* * *}$ & $.003^{* * *}$ & $.073^{* * *}$ & $.108^{* * *}$ \\
\hline
\end{tabular}

$\stackrel{\text { All Countries }}{{ }^{* * *} p<.001 .,{ }^{* * *} p<.01,{ }^{*} p<.05}$

Table 6. Regression results for explaining variance in aggression scores; Step 1 - Age and gender; Step 2 - age, gender, and exposure; Step 3 - Age, gender, exposure, and attitudes

\begin{tabular}{lcccc}
\hline & Step $1 R^{2}$ & Step $2 \Delta R^{2}$ & Step $3 \triangle R^{2}$ & Total $R^{2}$ \\
\hline Bangladesh & .014 & $.010^{*}$ & $.065^{* * *}$ & $.088^{* * *}$ \\
China & .009 & $.019^{* *}$ & $.095^{* * *}$ & $.123^{* * *}$ \\
Kenya & $.045^{* * *}$ & .005 & $.017^{* *}$ & $.067^{* * *}$ \\
Thailand & .018 & .000 & $.075^{* * *}$ & $.093^{* * *}$ \\
UK & $.021^{*}$ & $.007^{*}$ & $.048^{* * *}$ & $.076^{* * *}$ \\
Vietnam & .006 & $<.001$ & $.061^{* * *}$ & $.067^{* * *}$ \\
All Countries & $.013^{* * *}$ & $<.001$ & $.029^{* * *}$ & $.042^{* * *}$ \\
${ }^{* * *} p<.001 .,{ }^{* *} p<.01,{ }^{*} p<.05$ & & &
\end{tabular}

Table 7. Regression results for explaining variance in lapse scores; Step 1 - Age and gender; Step 2 age, gender, and exposure; Step 3 - Age, gender, exposure, and attitudes

\begin{tabular}{|c|c|c|c|c|}
\hline & Step $1 R^{2}$ & Step $2 \Delta R^{2}$ & Step $3 \Delta R^{2}$ & Total $R^{2}$ \\
\hline Bangladesh & $.024^{*}$ & .003 & $.044^{* * *}$ & $.072^{* * *}$ \\
\hline China & .011 & .002 & $.141^{* * *}$ & $.154^{* * *}$ \\
\hline Kenya & $.060^{* * *}$ & $.016^{* *}$ & $.008^{*}$ & $.084^{* * *}$ \\
\hline Thailand & .018 & .002 & $.088^{* * *}$ & $.108^{* * *}$ \\
\hline$U K$ & $.078^{* * *}$ & .002 & $.074^{* * *}$ & $.157^{* * *}$ \\
\hline Vietnam & .012 & .001 & $.071^{* * *}$ & $.084^{* * *}$ \\
\hline All Countries & $.030^{* * *}$ & .001 & $.057^{* * *}$ & $.088^{* * *}$ \\
\hline
\end{tabular}


To assess the interaction effects between country and attitude score on violations, aggressions, and lapses (in order to ascertain whether the effect of attitudes on self-reported behaviours differed significantly across country samples), an additional series of linear multiple regression analyses were conducted that included interaction terms. All variables were entered into one block; gender, age, and country were dummy coded, and interaction terms for each country created by multiplying its dummy code with attitude score. Figure 3 shows the extent to which variance in each PBQ factor score was explained by attitudes score in each country, after controlling for age, gender, and exposure effects. In other words, when age, gender, and exposure are held constant, for each one unit increase in attitudes score (signifying safer attitudes), the PBQ scale score decreased (signifying safer behaviours) by the amount shown in the graphs (i.e., absolute, unstandardised B coefficients are shown).

Exploration of interaction effects revealed significant differences between a number of countries in the extent to which attitudes scores explained variance in the three behavioural factors (after taking age, gender, and exposure to the road environment into account). In China, attitudes explained variation in violations scores to a significantly greater extent than in any other country except Vietnam; this difference was significant at $p=.010$ when comparing with Thailand, $p=.001$ when comparing to the UK, and at $p<.001$ for Bangladesh and Kenya. Significant differences were also found between Vietnam and Bangladesh $(p<.001)$, Vietnam and the UK $(p=.025)$, Vietnam and Kenya $(p<.001)$, Kenya and Thailand $(p=.029)$, and Kenya and the UK $(p=.029)$.

It was also found to be the case that in the China sample attitudes score explained variance in aggressions score to a significantly greater extent than in any other country, all at $p<.001$. No other significant differences were found. Regarding lapses, it was found that attitudes score explained variance in the pedestrian behaviour score to a significantly greater extent in China than in any other country; this was true at $p<.001$ for all comparisons except with the UK sample, where the difference was significant at $p=.001$. It was also found that in the Kenya sample attitudes score explained variance in Lapses score to a significantly lesser extent than in Bangladesh $(p=.019)$, the UK $(p=.004)$, and Vietnam $(p=.010)$. 


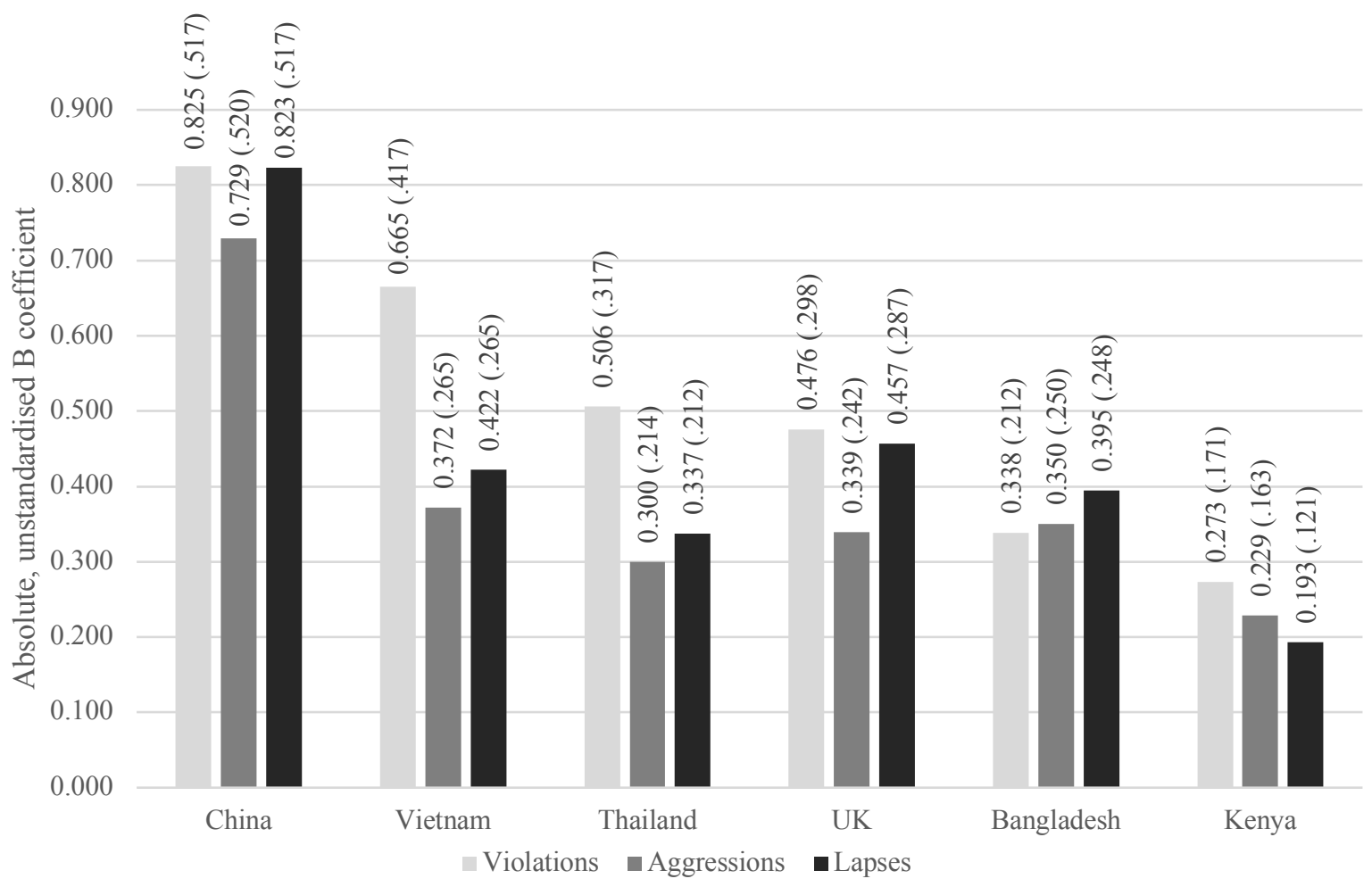

Figure 3. Absolute, unstandardised regression weights for the prediction of PBQ factor scores (violations, aggressions, lapses) based on attitudes score broken down by country, after controlling for age, gender, and exposure to the road environment (standardised coefficients are shown in brackets following the unstandardised values)

\section{Discussion}

This research has investigated a person's attitudes to risk and rule violating on-road behaviours in six countries, finding significant differences between many of them. The research has also assessed the extent to which these attitudes to traffic safety explained variance in the self-reported pedestrian behaviour of road users across those countries. After accounting for age, gender, and exposure differences, results show these types of attitudes to explain variance in self-reported pedestrian behaviours to a significant extent in all countries investigated, but that they do so to a significantly greater degree in some countries compared to other countries. Our hypothesis, that these types of attitudes would relate to self-reported pedestrian behaviour in all countries, but would do so to a lesser extent in lower-income countries, was partially supported. 


\subsection{Differences in attitudes}

Rather than focus on attitudes towards the behaviours of specific road user groups (e.g., driver, motorcyclist, or road crossing behaviours), we measured respondents' general attitudes to traffic safety, including questions about traffic rules as a whole, choices made as a passenger or motorcyclist, as well as those concerning the way drivers (of any vehicle) behave. In terms of the differences between country samples, it was found that Kenyan respondents reported the safest attitudes to traffic safety, Vietnamese respondents the least safe attitudes, and UK respondents (i.e., those from the country with the 'safest' road system of those investigated; WHO, 2018) somewhere in the middle.

Comparing with previous literature, Nordfjærn et al. (2011; 2014), found drivers from the safest country (i.e., Norway) to hold the safest attitudes regarding drink driving and speeding, but less safe attitudes than their Sub-Saharan, Indian, and Russian counterparts when looking at rule violations and attitudes to pedestrians. Nordfjærn et al. explained their findings in terms of 1) successful traffic campaigns in Norway about speeding and drink driving (hence safe driving attitudes), and 2) the lack of clear regulation, and adherence to that regulation, in lower income countries (hence complicating the measurement of attitude to rule violations). The attitudes scale presented in the current research did not distinguish between different classes of attitudes, rather measured one global score, including within it attitudes to rule violations and to speeding. This was empirically found to be appropriate; however, the possibility exists that, had some questions been investigated separately, different patterns may have been found. It is true that regulations are less clear, and less enforced in Kenya than in the UK, hence Nordfjærn et al.'s explanation is consistent with our findings in that respect; however, the same is true in Bangladesh and Vietnam, countries that we have found to be home to respondents with the least safe attitudes. There are a great many factors that can influence an individual's attitudes; we would argue, based on the results presented above, that a lack of regulation and a series of successful campaigns is not a satisfactory explanation for differences in attitudes to traffic safety.

\subsection{Differences in relationships}

The lack of clarity around the source of the differences in attitudes to road safety across countries is not necessarily problematic. Taken alone, a measurement of a group of people's attitudes to traffic safety is not particularly informative in terms of guiding road safety intervention design; the utility of this information comes in its relationship with behaviour, as knowledge of this can help to guide road safety campaign focus across cultural settings. As 
Lund and Rundmo (2009) pointed out, if attitudes to traffic safety do not predict behaviour, safety campaigns may be unsuccessful (due to their nature of being largely based on affecting attitudes; see Phillips et al. 2011). In their investigation of driver behaviour, Lund and Rundmo (2009) found attitudes to predict behaviour to a lesser extent in Ghana than in Norway. Nordfjærn et al. $(2011 ; 2014)$ found similar results when expanding to compare responses from individuals in three Sub-Saharan African countries (i.e., Tanzania, Ghana, Uganda) with those from individuals in Russia and India (analysed as one group), Turkey and Iran (also analysed as one group), and Norway. Attitudes explained variance in driver behaviour in Norway and Russia/India, but not in the other country groups.

Although we looked at pedestrian behaviour rather than driver behaviour (in order to minimise bias in less motorized countries), our results were at least in part in line with those reported by Lund and Rundmo (2009) and Nordfjærn and colleagues (2011; 2014). The link between attitudes and the self-reported tendency to perform memory and attention errors, and intentional rule violations, was indeed weaker in Kenya (a lower-income, Sub-Saharan African country) than in the UK (a high-income, North European country with a 'safe' road system). This was after accounting for the effects of age, gender, and the number of hours a respondent spent travelling each week. This finding, that attitudes explained variance in selfreported behaviours to a lesser extent in Kenya than in the other countries, was found to be significant for the majority of pairwise comparisons for the violations and lapses behavioural factors. Although these country comparisons were not found to be statistically significant, the same pattern was seen in the aggressions factor. Taken as a whole, results suggest that behaviours performed when interacting with the road system as a pedestrian are related to a person's general attitudes towards rule violating or risky on-road behaviours to a lesser extent in Kenyan than in the other five countries.

In the introduction, the hypothesis was made that the attitudes-behaviour link would be weaker in lower income countries. Kenya is one of the two lowest-income countries of the six included in this research (the other being Bangladesh), hence results concerning that sample are in support of our hypothesis; however, the trend does not hold for the other countries. The only additional finding that is in line with that hypothesis is that the link between Bangladeshi respondents' traffic safety attitudes and their self-reported tendency to perform intentional rule violations was also weak. The UK, the highest-income country of the group, was not the country in which attitudes were most strongly associated with behaviour, rather it was in the China sample where this link was stronger than in any other country. This difference was found to be significant for all three classes of pedestrian behaviour, for the 
majority of country pair comparisons. Thailand and Vietnam are both middle-income countries, yet in those countries the link between attitudes and self-reported behaviour was in many cases stronger than in the UK. Overall, no strong associations between country income level and attitudes-behaviour links were seen (in contrast to patterns seen in Nordfjærn and colleagues' (2011; 2014) work).

Results suggest that the link between attitudes and behaviours is much more complex than a question of country income or development. As described in the introduction, the six countries included in our analyses (chosen due to their involvement in a larger project; NIHR, 2017) differ greatly in many aspects. Indeed, part of the reason they were chosen to be part of the project was because of these differences; they represent a relatively wide spectrum in terms of culture, politics, economics, road safety statistics, and geography (though with some notable omissions, for example the Americas). As such, each country has quite different road traffic policies, and quite different road environments. Although very generally speaking a country's income relates to its road safety statistics (with those countries with lower incomes generally having poorer road safety records; WHO, 2018), the picture is far more complicated than those figures alone can reveal.

National income is related to road safety in a number of ways, for example through its effect on policing levels, infrastructure quality, and the prevalence of safety technologies; however, there is more to road safety than simply the money a nation is able to spend. Irrespective of income, different countries have different safety cultures, different political goals, different economic drivers. The aim of the current research was to look only at the link between attitudes to on-road rule violating or risky behaviours and self-reported pedestrian behaviours in road users across different countries, hence in the statistical analyses presented above we did not include variables relating to economics, politics, or road traffic culture. These aspects, however, undoubtedly affect the behaviour of a country's road users. For example, given the almost complete lack of safe pedestrian facilities in Bangladesh and Kenya, it is perhaps unsurprising that attitudes are not as strongly linked to behaviour. Regardless of one's attitudes to towards performing risky or rule violating behaviours when interacting with the road system, unfavourable environmental conditions may force what might be considered risky behaviours (and vice versa; e.g., Cepolina et al. 2018).

Despite the statistical significance reached, it is worth pointing out that the amount of variance in pedestrian behaviour explained by attitudes (after controlling for age, gender, and exposure) was quite small in comparison to previous studies of attitudes and behaviour. The largest amount of variance explained by attitudes in any pedestrian behaviour factor was in 
Thailand and Vietnam for the violations factor, both at around $17 \%$. The only other instances in which attitudes explained more than $10 \%$ of the variance in behaviour were in China (true for violations and lapses). A likely explanation for this is that the attitudes questions were related to general traffic behaviours, most of which referred to vehicle driving behaviours; they were not specifically about attitudes to aberrant pedestrian behaviour. The predictive ability of attitudes is strongest when those attitudes are very specifically about the behaviours being predicted (e.g., Ajzen, 1991) rather than general attitudes in the same wider domain (such as was the case in the current research). The link between self-reported behaviour and attitudes to those behaviours has been shown in the driver domain (e.g., Ulleber \& Rundmo, 2003; Iversen \& Rundmo, 2004), and in the pedestrian domain (Nordfjærn \& Zavareh, 2016). Additionally, reports of risky pedestrian behaviours have been shown to be very closely related to reports of risky driver behaviour (Şimşekoğlu, 2015); however, the relationship between pedestrian behaviours and attitudes to general road traffic safety (even when including questions regarding behaviours as passengers, e.g., 'I will ride with someone who speeds if others do', used above) is not as strong as the relationships seen elsewhere (though a significant link does still exist). Moving forward with this research, a replication of Nordfjærn and Zavareh's (2016) or Şimşekoğlu's (2015) approach (in which specific attitudes to aberrant pedestrian behaviours were surveyed) across countries, combined with an investigation of driver attitudes and behaviours, could serve to explore further the potential relationships therein, and how these might differ from relationships between general traffic safety attitudes and pedestrian behaviours (i.e., those studied here).

Our results also showed differences in the extent to which age and gender predicted pedestrian behaviours, across all three behavioural factors. Although not part of our initial hypotheses, hence not tested statistically, it can be seen from Table 5 that age and gender were more strongly predictive of the three pedestrian behavioural factors in Kenya and the UK than in any other country (where significance was often not reached, and where it was, it did so to a lesser extent). Relationships between age, gender, and risky behaviours on the road have been shown in both the driver behaviour domain (e.g., Reason et al. 1990; Parker et al. 1995), and in pedestrian behaviour (e.g., Granié et al. 2013; Deb et al. 2017). Moreover, younger males have also been shown to exhibit more risky attitudes to driver behaviours (e.g., Starkey et al. 2016) and pedestrian behaviours (e.g., Lennon et al. 2017) then females or older males. Although our results tentatively suggest that these relationships and effects differ across cultures or countries, we are not currently aware of any study that has specifically investigated this topic. 


\subsection{Limitations}

The most significant limitation to this research is in the sample. First, a bias towards young, educated, affluent members of society was seen, particularly in the Bangladesh, China, and Kenya samples. This was especially pronounced in the Kenya sample, where the large majority of respondents were from a university environment in Nairobi. This age group is the most highly represented in accident statistic in Kenya, hence is certainly of interest in road safety research; however, the sample does not capture the 'average' Kenya or Nairobi resident. Additional research would be required to assess whether the relationships found above also hold for those from rural settings, those from relatively less affluent backgrounds, and those with lower levels of education. Similarly, the were large gender differences in the samples, and, more importantly, the biases were not the same across countries; for example, males were more highly represented in the Bangladesh sample, whereas the Thai sample had a larger proportion of females. These differences would have been partly due to differences in the sampling methods used in each country. Although we endeavoured to use similar methods to those used elsewhere in the literature (e.g., Şimşekoğlu et al. 2012, Nordfjærn et al. 2012, Deb et al. 2017, Granié et al. 2013), differences in available expertise and resources, and in the requirements of working in the different settings, strongly influenced the sampling methods used. Although we accounted for gender, age, and exposure differences in the regression models, we cannot be fully certain that they did not affect our results.

Additionally, although we accounted for respondent's exposure to the road system (i.e., the number of hours they spent travelling each week), we did not account for their primary choice of transport mode. As would be expected, there were very large differences across countries for this demographic variable, reflecting differences in the nature of the road systems of the different countries. The aim of the current research was to assess, across road users, the extent to which self-reported, risky behaviours related to general attitudes to traffic safety. An important reason for measuring self-reported pedestrian behaviour was that virtually all road user groups are able, and typically do, interact with the road system as a pedestrian at some point in their daily or weekly routine. As such, a measure of pedestrian behaviour is far more inclusive than one focussing on driver or rider behaviour (where far fewer people drive or ride motorbikes, and rates differ across countries). Although it is true that individuals behave as a pedestrian to different extents in different settings (e.g., Bassett et al. 2008), this bias is less pronounced than for other forms of transport. Looking at differences in behaviours, attitudes, and other factors in specific road user groups in different 
countries (e.g., motorcycle riders in Vietnam compared to those in the UK) would certainly be of interest. It would also be of interest to assess how pedestrian behaviours differ across road user groups within individual countries, as was undertaken by Xu et al. (2018) in China. This was not, however, within the scope of the present study.

Relatedly, although actions made when acting as a pedestrian was our measure of traffic safety behaviour, we purposely chose to measure people's attitudes towards the risky and rule violating behaviours of motorised transport users (worded so as to also be relevant to those not able to drive). This was for reasons already described, i.e., that most interact with other, motorised modes of transport even if they do not drive themselves (hence have attitudes of interest and some level of influence over those users), but most cannot respond to a car driver behaviour questionnaire. It must be acknowledged, however, that a person's experience using motorised transport could affect their attitudes concerning another's use of said vehicle (be it car, bus, motorcycle, etc.). It would be of interest, therefore, to explore how attitudes to rule following and the risky use of motorised transport might differ between people with different levels of experience with various modes of transport. Given differences between countries in modal share and use, exploring such measures may shed more light on the sources of the country differences found here. Although these aspects were outside of the scope of the work presented here, we accept the lack of such measures as a limitation of the current work.

To return to behaviour (rather than attitudes), a final limitation is that we did not include a measure specifically asking about the amount of time (or distance) each respondent spent interacting with the roads system as a pedestrian (our exposure measure was worded more generally). This may have introduced a bias in the results, insofar as some respondents will have had more experience as a pedestrian than others. As such, some respondents could have had greater experience to draw on when answering behaviour questions, where others may be drawing more on speculation of what they would do given they walked more. We must also accept that this bias is unlikely to be equal across nations.

A wider issue with all uses of self-report measures of this type is that a person's memory of their past behaviour must be relied upon. The many flaws of human memory have been well documented; hence, the measure can only provide an imperfect, subjective (as opposed to measured, objective) indication of past performance. This is compounded by the wording of the possible response options, insofar as a respondent is required to indicate frequency of actions in words (e.g., 'very infrequently' or 'very often'), rather than numbers (e.g., twice a week). It may be that to one person, 'very frequently' is five times a week, 
while to another it would be ten. This issue is not unique to the current study, rather exists for all measures using Likert scales of this design. A potential solution to these issues, and to that of experience as a pedestrian, above, would of course be to use observed activities, rather than self-reports, as the measure of pedestrian behaviour. An ideal approach would be to combine recorded accident statistics with (ideally covert) observations of real-world behaviour, alongside surveys of attitudes, using the same individuals. This would, however, be exceptionally difficult, especially in LMICs (where accident records are often lacking), and may be ethically problematic.

\subsection{Conclusions}

Study limitations notwithstanding, this research has shown that attitudes to traffic rule violations and risky traffic behaviours are significantly associated with self-reported pedestrian behaviours in Bangladesh, China, Kenya, Thailand, the UK, and Vietnam. It has also shown that these links are stronger in some countries than in others; in Kenya in particular, traffic safety attitudes explained variance in self-reported behaviours to a significantly lesser extent, while in China the link was significantly stronger than in any other countries. This holds for all three behavioural factors analysed, namely intentional rule violations, aggressive behaviours, and memory or attentional lapses. These results were found after controlling for age, gender, and exposure to the road system, factors that were also shown to have different effects on behaviour across the six countries. In particular, results suggest that age and gender are stronger predictors of pedestrian behaviours in Kenya and the UK than in the other countries.

Similar results have been seen elsewhere in the driving literature; however, this study also adds to the currently limited (nevertheless increasing) literature on pedestrian behaviour, and does so using a sample of over 3,400 individuals. This is larger than the majority of other, similar studies in the extant literature. We conclude, therefore, that not only are attitudes to specific pedestrian behaviours associated with performance of those behaviours (shown in the existing literature; Nordfjærn and Zavareh, 2016; Şimşekoğlu, 2015), but also that a person's attitudes concerning risky or rule violating behaviours when in control of a motorised form of transport are associated with the way they report behaving as a pedestrian (though perhaps to a lesser extent; additional work would be needed to examine this empirically).

The inter-country differences suggest that road safety interventions based on affecting attitudes might be more effective at reducing aberrant pedestrian behaviours in China 
compared to other countries, while similarly designed interventions would be less effective in Kenya. Although we hypothesised that the attitudes-pedestrian behaviour link would be stronger in higher income countries compared to low- and middle-income countries, the relationships were more complex; this points to the need to understand the specific cultural context in question before designing interventions aimed at influencing behaviour in those contexts.

We would also suggest that public information campaigns, targeted training programmes, or educational interventions that foster safer general road safety attitudes would contribute to safer pedestrian behaviours, but that targeted pedestrian behaviour campaigns would likely do so to a greater extent. This could be particularly important in many low- and middle-income countries where a greater majority of people do not have access to a vehicle, and are therefore required to assume the role of pedestrian. That said, there is clearly more work to be done in those settings; attitudes are only one part of a complex set of factors underlying behaviour, and road user behaviour is only one aspect of the highly complex sociotechnical system that is road transport (McIlroy et al. 2019a).

\section{Acknowledgements}

This research was commissioned by the National Institute for Health Research using Official Development Assistance (ODA) funding. The views expressed are those of the authors and not necessarily those of the NHS, the NIHR, or the Department of Health and Social Care. We would like to thank Mithun Debnath, Shahnewaz Hasnat-E-Rabbi, Omar Faruqe Hamim, Kezhen Hu, Linyang Wang, Mingyu Liu, James Oyoo, Sylvia Anyika, Dinh Do Duy, Rish Arora, and Tayyib Goolamallee for all their help in gathering data.

\section{References}

Åberg, L. (1993). Drinking and driving: intentions, attitudes, and social norms of Swedish male drivers. Accident Analysis \& Prevention, 25, 289-296.

Ajzen, I. (1991). The theory of planned behavior. Organizational Behavior and Human Decision Processes, 50, $179-211$.

Allport, G.W. (1935). Attitudes. In A Handbook of Social Psychology (pp. 798-844). Worcester, MA, US: Clark University Press.

Antić, B., Pešić, D., Milutinović, N., \& Maslać, M. (2016). Pedestrian behaviours: Validation of the Serbian version of the pedestrian behaviour scale. Transportation Research Part F: Traffic Psychology and Behaviour, 41, 170-178.

Assum, T. (1997). Attitudes and road accident risk. Accident Analysis \& Prevention, 29, 153-159. 
Bassett, D.R., Pucher, J., Buehler, R., Thompson, D.L., \& Crouter, S.E. (2008). Walking, cycling, and obesity rates in Europe, North America, and Australia. Journal of Physical Activity and Health, 5, 795-814.

Brislin, R. (1970) Back-translation for cross-cultural research. Journal of Cross-Cultural Psychology, 1, 185216.

Cepolina, E.M., Menichini, F., \& Rojas, P.G. (2018). Level of service of pedestrian facilities: Modelling human comfort perception in the evaluation of pedestrian behaviour patterns. Transportation Research Part F: Traffic Psychology and Behaviour, 58, 365-381.

Cestac, J., Paran, F., \& Delhomme, P. (2011). Young drivers'sensation seeking, subjective norms, and perceived behavioral control and their roles in predicting speeding intention: How risk-taking motivations evolve with gender and driving experience. Safety Science, 49, 424-432.

Cestac, J. \& Delhomme (Eds.) (2012). European road users' risk perception and mobility. The SARTRE 4 survey. Lyon, France: Public Imprim.

Chen, C.F. (2009). Personality, safety attitudes and risky driving behaviors_Evidence from young Taiwanese motorcyclists. Accident Analysis \& Prevention, 41, 963-968.

De Pelsmacker, P., \& Janssens, W. (2007). The effect of norms, attitudes and habits on speeding behavior: Scale development and model building and estimation. Accident Analysis \& Prevention, 39, 6-15.

De Winter, J.C.F., \& Dodou, D. (2010). The Driver Behaviour Questionnaire as a predictor of accidents: A meta-analysis. Journal of Safety Research, 41, 463-470.

Deb, S., Strawderman, L., DuBien, J., Smith, B., Carruth, D.W., \& Garrison, T.M. (2017). Evaluating pedestrian behavior at crosswalks: Validation of a pedestrian behavior questionnaire for the US population. Accident Analysis \& Prevention, 106, 191-201.

Dinh D.D., Vu N.H., McIlroy R.C., Plant K.A., Stanton N.A. (Under Review) Examining the roles of multidimensional fatalism on traffic safety attitudes and pedestrian behaviour. Safety Science

DfT (2017). Reported Road Casualties Great Britain: 2016 Annual Report. London: Department for Transport.

Díaz, E. M. (2002). Theory of planned behavior and pedestrians' intentions to violate traffic regulations. Transportation Research Part F: Traffic Psychology and Behaviour, 5, 169-175.

Ertz, M., Karakas, F., \& Sarigöllü, E. (2016). Exploring pro-environmental behaviors of consumers: An analysis of contextual factors, attitude, and behaviors. Journal of Business Research, 69, 3971-3980.

Evans D., \& Norman P. (1998). Understanding pedestrians' road crossing decisions: an application of the theory of planned behaviour. Health Education Research, 13, 481-489.

Field, A. (2018). Discovering Statistics Using SPSS, $5^{\text {th }}$ Ed. Sage Publications.

Fishbein, M., \& Ajzen, I. (1980). Understanding attitudes and predicting social behavior. Englewood Cliffs, NJ: Prentice-Hall.

GRSF \& IHME (2014). Transport for Health: The Global Burden of Disease from Motorized Road Transport. Seattle, WA: IHME; Washington, DC: The World Bank.

Hooper, D., Coughlan, J., \& Mullen, M. (2008). Structural Equation Modelling: Guidelines for Determining Model Fit. The Electronic Journal of Business Research Methods, 6, 53-60.

Hoque, M.M., \& Salehin, M.F. (2013). Vulnerable road users' (VRUs) safety in Bangladesh. Presented at $16^{\text {th }}$ Road Safety on Four Continents Conference, Beijing, China, 15-17 May, 2013. 
Hu, L.T., \& Bentler, P.M. (1999). Cutoff Criteria for Fit Indexes in Covariance Structure Analysis: Conventional Criteria Versus New Alternatives. Structural Equation Modelling, 6, 1-55.

Iversen, H. (2004). Risk-taking attitudes and risky driving behaviour. Transportation Research Part F: Traffic Psychology and Behaviour, 7, 135-150.

Iversen, H., \& Rundmo, T. (2004). Attitudes towards traffic safety, driving behaviour and accident involvement among the Norwegian public. Ergonomics, 47, 555-572.

Lennon, A., Oviedo-Trespalacios, O., \& Matthews, S. (2017). Pedestrian self-reported use of smart phones: Positive attitudes and high exposure influence intentions to cross the road while distracted. Accident Analysis \& Prevention, 98, 338-347.

Lund, I.O. (2006). Attitudes as predictors of driver behaviour in Norway and Ghana. NTNU, Department of Psychology, Trondheim.

Lund, I.O., \& Rundmo, T. (2009). Cross-cultural comparisons of traffic safety, risk perception, attitudes and behaviour. Safety Science, 47, 547-553.

Machin, M.A., \& Sankey, K.S. (2008). Relationships between young drivers' personality characteristics, risk perceptions, and driving behaviour. Accident Analysis \& Prevention, 40, 541-547.

Mallia, L., Lazuras, L., Violani, C., \& Lucidi, F. (2015). Crash risk and aberrant driving behaviors among bus drivers: the role of personality and attitudes towards traffic safety. Accident Analysis \& Prevention, 79, $145-151$.

Mamo, W.G., \& Haney, D.M. (2014). Attitudes and behaviors regarding traffic regulations in Addis Ababa, Ethiopia. International Perspectives in Psychology: Research, Practice, Consultation, 3, 37.

McIlroy, R.C., Plant, K.A., Hoque, M.S., Wu, J., Kokwaro, G.O., Nam, V.H., \& Stanton, N.A. (2019a). Who is responsible for global road safety? A cross-cultural comparison of Actor Maps. Accident Analysis \& Prevention, 122, 8-18.

McIlroy, R.C., Plant, K.A., Jikyong, U., Vũ, N.H., Bunyasi, B., Kokwaro, G.O., Wu, J., Hoque, M.S., Preston, J.M., \& Stanton, N.A. (2019b). Validating the Pedestrian Behaviour Questionnaire in six countries. Accident Analysis \& Prevention.

Mirzaei, R., Hafezi-Nejad, N., Sabagh, M.S., Moghaddam, A.A., Eslami, V., Rakhshani, F., \& RahimiMovaghar, V. (2014). Dominant role of drivers' attitude in prevention of road traffic crashes: A study on knowledge, attitude, and practice of drivers in Iran. Accident Analysis \& Prevention, 66, 36-42.

Mohamed, M., \& Bromfield, N.F. (2017). Attitudes, driving behavior, and accident involvement among young male drivers in Saudi Arabia. Transportation Research Part F: Traffic Psychology and Behaviour, 47, 59-71.

Nabi, H., Salmi, L. R., Lafont, S., Chiron, M., Zins, M., \& Lagarde, E. (2007). Attitudes associated with behavioral predictors of serious road traffic crashes: results from the GAZEL cohort. Injury Prevention, 13, 26-31. NIHR (2017).

NIHR (2017) Global Health Research Group on Road Safety, University of Southampton. https://www.fundingawards.nihr.ac.uk/award/16/137/122. Accessed on the $28^{\text {th }}$ of August, 2019.

Nordfjærn, T., Jørgensen, S., \& Rundmo, T. (2011). A cross-cultural comparison of road traffic risk perceptions, attitudes towards traffic safety and driver behaviour. Journal of Risk Research, 14, 657-684.

Nordfjærn, T., \& Şimşekoğlu, Ö. (2013). The role of cultural factors and attitudes for pedestrian behaviour in an urban Turkish sample. Transportation Research Part F: Traffic Psychology and Behaviour, 21, 181-193.

Nordfjærn, T., \& Şimşekoğlu, Ö. (2014). Empathy, conformity, and cultural factors related to aberrant driving behaviour in a sample of Urban Turkish drivers. Safety Science, 68, 55-64. 
Nordfjærn, T., Şimşekoğlu, Ö., \& Rundmo, T. (2014). Culture related to road traffic safety: a comparison of eight countries using two conceptualizations of culture. Accident Analysis \& Prevention, 62, 319-328.

Nordfjærn, T., \& Zavareh, M. F. (2016). Individualism, collectivism and pedestrian safety: A comparative study of young adults from Iran and Pakistan. Safety Science, 87, 8-17.

Nunnally, J. (1978). Psychometric methods. New York: McGraw-Hill.

Papadimitriou, E., Theofilatos, A., \& Yannis, G. (2013). Patterns of pedestrian attitudes, perceptions and behaviour in Europe. Safety Science, 53, 114-122.

Parker, D., Manstead, A.S., Stradling, S.G., \& Reason, J.T. (1992). Determinants of intention to commit driving violations. Accident Analysis \& Prevention, 24, 117-131.

Parker, D., Reason, J.T., Manstead, A.S., \& Stradling, S.G. (1995a). Driving errors, driving violations and accident involvement. Ergonomics, 38, 1036-1048.

Parker, D., West, R., Stradling, S., \& Manstead, A.S. (1995b). Behavioural characteristics and involvement in different types of traffic accident. Accident Analysis \& Prevention, 27, 571-581.

Parker, D., Manstead, A.S., \& Stradling, S.G. (1995). Extending the theory of planned behaviour: The role of personal norm. British Journal of Social Psychology, 34, 127-138.

Peltzer, K., \& Renner, W. (2003). Superstition, risk-taking and risk perception of accidents among South African taxi drivers. Accident Analysis \& Prevention, 35, 619-623.

Phillips, R. O., Ulleberg, P., \& Vaa, T. (2011). Meta-analysis of the effect of road safety campaigns on accidents. Accident Analysis \& Prevention, 43, 1204-1218.

Poulter, D.R., Chapman, P., Bibby, P.A., Clarke, D.D., \& Crundall, D. (2008). An application of the theory of planned behaviour to truck driving behaviour and compliance with regulations. Accident Analysis \& Prevention, 40, 2058-2064.

Reason, J., Manstead, A., Stradling, S., Baxter, J., \& Campbell, K. (1990). Errors and violations on the roads: a real distinction?. Ergonomics, 33(10-11), 1315-1332.

Rosenbloom, T., Nemrodov, D., Barkan, H., 2004. For heaven's sake follow the rules: pedestrians' behavior in an ultra-orthodox and a non-orthodox city. Transport. Res. Part F: Traffic Psychol. Behav. 7, $395-404$.

Şimşekoğlu, Ö. (2015). How do attitudes, personality traits, and driver behaviors relate to pedestrian behaviors?: A Turkish case. Traffic Injury Prevention, 16, 84-89.

Starkey, N.J., \& Isler, R.B. (2016). The role of executive function, personality and attitudes to risks in explaining self-reported driving behaviour in adolescent and adult male drivers. Transportation Research Part F: Traffic Psychology and Behaviour, 38, 127-136.

Ulleberg, P., \& Rundmo, T. (2003). Personality, attitudes and risk perception as predictors of risky driving behaviour among young drivers. Safety Science, 41(5), 427-443.

West, R., \& Hall, J. (1997). The role of personality and attitudes in traffic accident risk. Applied Psychology, 46, 253-264.

WHO (2018). Global Status Report on Road Safety 2018. World Health Organisation: Geneva.

World Bank (2019). World Bank Country and Lending Groups. https://datahelpdesk.worldbank.org/knowledgebase/articles/906519-world-bank-country-and-lendinggroups. Accessed $17^{\text {th }}$ January, 2019. 
Xu, J., Liu, J., Qu, W., Ge, Y., Sun, X., \& Zhang, K. (2018). Comparison of pedestrian behaviors between drivers and non-drivers in Chinese sample. Transportation research part $F$ : traffic psychology and behaviour, 58, 1053-1060.

Yao, L., \& Wu, C. (2012). Traffic safety for electric bike riders in China: attitudes, risk perception, and aberrant riding behaviors. Transportation Research Record, 2314, 49-56.

Zhou, R., Horrey, W.J., (2010). Predicting adolescent pedestrians' behavioural intentions to follow the masses in risky crossing situations. Transportation Research Part F: Traffic Psychology and Behaviour, 13, $153-163$.

Zimbardo, P.G., \& Leippe, M R. (1991). The psychology of attitude change and social influence. Mcgraw-Hill Book Company. 